\title{
(When) are religious people nicer? Religious salience and the "Sunday Effect" on pro-social behavior
}

\author{
Deepak Malhotra* \\ Harvard Business School
}

\begin{abstract}
Prior research has found mixed evidence for the long-theorized link between religiosity and pro-social behavior. To help overcome this divergence, I hypothesize that pro-social behavior is linked not to religiosity per se, but rather to the salience of religion and religious norms. I report a field experiment that examined when auction participants will respond to an appeal to continue bidding for secular charitable causes. Religious individuals are more likely than non-religious individuals to respond to an appeal "for charity" only on days that they visit their place of worship; on other days of the week, religiosity has no effect. Notably, the result persists after controlling for a host of factors that may influence bidding, but disappears when the appeal "for charity" is replaced by an appeal to bid for other (i.e., competitive) reasons. Implications for the link between religion and pro-social behavior are discussed.
\end{abstract}

Keywords: religion, charity, Sunday Effect, auction.

\section{Introduction}

Psychologists, sociologists, anthropologists, and religious scholars (e.g., Smith, 1891; James, 1902; Durkheim, 1912; Freud, 1927; Allport, 1950; EvansPritchard, 1965; Skinner, 1969) have long posited a link between religiosity, defined as the degree to which one is involved in religious activities (e.g., prayer, church attendance, etc.) and pro-social behavior (e.g., charitable giving, altruism, cooperation, helping, and volunteering). Consistent with this, empirical investigations have repeatedly demonstrated that religiosity is a key predictor of self-reported pro-social behavior (Friedrichs, 1960; Langford \& Langford, 1974; Morgan, 1983; Koenig, McGue, Krueger, \& Bouchard, 2007). However, when actual behavior (rather than self-reporting) is studied, the link between religiosity and pro-social behavior disappears, or becomes extremely tenuous (Cline \& Richards, 1965; Darley \& Batson, 1973; Smith, Wheeler, \& Diener, 1975; Annis, 1976; Batson \& Ventis, 1982; Batson, Oleson, Weeks, Healy, Reeves, Jennings, \& Brown, 1989). Because self-reports are more likely than spontaneous behaviors to reflect a social desirability bias (Batson \& Ventis, 1982), some have argued that religiosity is less linked to actual pro-social behaviors than it is to the desire to be seen by others (and to see oneself) as pro-social (e.g., Batson, Schoenrade, \& Ventis, 1993). This paper considers an alternative relationship between religiosity and

\footnotetext{
* Address: Deepak Malhotra, Harvard Business School, Baker Library, Room 471, Soldiers Field Boston, MA 02163. Email: dmalhotra@hbs.edu.
}

pro-social behavior, one that may help to explain this discrepancy.

I hypothesize that pro-social behavior is linked not to religiosity per se, but rather to the salience of religion and religious norms (Shariff \& Norenzayan, 2007). Because religious people are more likely to be in situations where religion is salient (e.g., in prayer, at church, etc.), they may in fact exhibit a greater propensity to behave prosocially (and to recall doing so in self-report surveys). However, this heightened tendency towards pro-social behavior will not necessarily extend to contexts in which religion is not salient, as is the case when behaviors are studied in laboratory experiments. In testing this hypothesis, the current investigation sets aside the oft-debated question, "Does religion make people nicer?", and instead asks, "When does religion make people nicer?"1 I report on a field experiment that assesses whether and when religious vs. non-religious auction participants respond to an appeal to continue bidding for (non-religious) charitable causes. The findings suggest that religious individuals are more likely to respond to an appeal for charity, but this effect is isolated to days on which they are likely to have attended their place of worship.

Prior research on the link between religion and prosocial behavior has insufficiently considered the role that environmental cues play in motivating behavior (Ross \& Nisbett, 1991; Bargh, Chen, \& Burrows, 1996; Berger,

\footnotetext{
${ }^{1}$ I use the term "nicer" somewhat loosely here; my interest, technically, is in evaluating pro-social behavior. Such behavior, while seeming "nice", could well be driven by factors other than niceness (e.g., a sense of obligation).
} 
Meredith, \& Wheeler, 2007). Environmental cues can have non-conscious effects on behavior in social (Kay, Wheeler, Bargh, \& Ross, 2004) as well as private (Aarts $\&$ Dijksterhuis, 2003) domains. Furthermore, stable individual characteristics (e.g., ideological beliefs) often fail to accurately predict behavior unless the task environment contains cues that will trigger the appropriate behavioral norms (Darley \& Batson, 1973). For example, Berger et al. (2007) find that voters are more likely to support an education initiative if their polling location (the environmental cue) happens to be a school (vs. some other location), and that this effect persists even after controlling for the voter's political views, demographic traits, and a host of other factors. These findings implicate the significant role that context plays in making behavioral norms salient.

More specifically, research on priming effects demonstrates that environmental cues can activate relevant constructs in memory - and make them more accessible (Higgins, 1996; Bargh, 2006). Activation can also spread to related constructs that, in turn, guide judgment and behavior (Collins \& Loftus, 1975). Berger and Fitzsimons (2008), for example, show that increased exposure to images of dogs can lead to increased activation and accessibility of a related category, "cats", and to more positive evaluations of the Puma brand of sneakers. Likewise, Hertel and Kerr (2001) show that when there is ambiguity regarding the appropriate decision (e.g., whether to favor one's in-group), people will rely on normative scripts for guidance; the more accessible norms are more likely to be retrieved and to influence decision making.

In the current context, I hypothesize that the link, if any, between religiosity and pro-social behaviors is to be found in the contextually triggered salience of religious norms. Entirely consistent with this thesis, individuals have been shown to behave more cooperatively when they have been (unconsciously) primed with words associated with God and religion (Shariff \& Norenzayan, 2007). There is also evidence to suggest that those who are "intrinsically religious" (e.g., those who pray frequently) — but not those who are "extrinsically religious" (e.g., those who are religious for social or political reasons) - tend to be more pro-social in secular aspects of life (Allport, 1966; Morgan, 1983; Watson, Hood, \& Morris, 1985; Koenig et al., 2007). These findings suggest that pro-social behavior may be associated less with religiosity (i.e., the degree to which one is religious) than it is with the extent to which religion is salient at a particular time (e.g., due to a recent or impending trip to church). When we couple this with the fact that religious people are more likely than non-religious people to be in situations where religion is salient (e.g., in prayer, at church or temple, etc.), this may help to explain why self-reported pro-social behavior is higher for religious people.
The current investigation presents an experimental methodology that is able to separate religiosity (viewed as a stable individual characteristic) from religious salience (triggered by contextual cues) in a natural field setting, and which allows us to test whether these factors predict actual pro-social behavior. This approach helps to shift away from seeking a simple answer to the question of whether religious people are nicer, and towards assessing when, if ever, religious people may be nicer.

\section{Study}

The context of the current investigation is online charity auctions in which the pro-social behavior in question entails charitable giving by bidders. Bidding in charity auctions may be motivated not only by the desire to acquire the auctioned item at a price below its perceived value, but also by (a) the desire to contribute to charity and/or (b) the desire to beat rival bidders ( $\mathrm{Ku}$, Malhotra, \& Murnighan, 2005; Malhotra, 2010). The unique feature of charity auctions is that all of these motivations result in the same behavior (i.e., continue bidding), which in turn results in the same outcome (i.e., an increased likelihood of submitting the winning bid and providing more money to charity). In this context, I introduce a request to continue bidding, either for charitable or competitive reasons. This request is made to bidders who have just been outbid, and who must now decide whether to continue bidding. The analysis tests whether — and under what conditions - appeals to charity differentially impact the behavior of religious vs. non-religious bidders. The appeal-to-compete message is included in the study to test for the possibility that our results are driven not by the effect of an appeal to act pro-socially (i.e., charitably), but due to the mere presence of an appeal to bid.

To introduce our charity vs. competitive appeals into a natural field setting, I collaborated with a (for-profit) U.S. firm that hosts dozens of online charity auctions each month. This firm agreed to alter the text of the electronic messages (e-mails) it sends to bidders once their current bid has been exceeded by a rival bidder. Two messages (one "charity-focused" and one "competitive") were composed. Both messages informed bidders that they had been outbid and could return to the auction website to continue bidding. The appeal-to-charity message included language designed to make charitable motivations salient: "We hope you will continue to support this charity by keeping the bidding alive. Every extra dollar you bid in the auction helps us accomplish our very important mission." The appeal-to-competition message included language designed to make competitive motivations salient: "The competition is heating up! If you hope to win, you will have to bid again. Are you up for 
the challenge?" The message sent to bidders alternated each day for a period of eight weeks. Accordingly, bidders received either "an appeal to charity" or "an appeal to compete", depending on the day that they happened to be outbid. ${ }^{2}$

I hypothesized that religious individuals would be more likely than non-religious individuals to re-bid in response to receiving the appeal-to-charity message, but that this difference would exist only on days that religious individuals attended their place of worship (the contextual cue). I made no specific predictions regarding the appeal-to-compete message (which is a control condition), other than to predict that it would not affect religious bidders differently on the day they worshiped.

\section{Method}

\subsection{Data}

The initial auction dataset consisted of 19,539 outbid events over eight weeks, associated with 7,499 distinct items. In order to assess bidder religiosity, a voluntary electronic survey was sent to all bidders who had earlier participated in any charity auction during the original 8week data collection effort. Participants were asked how often they attended a place of religious worship (never, rarely, occasionally, or regularly) $)^{3}$ as well as the day of the week on which they were likely to attend. Because most attendees $(73.2 \%)$ identified Sunday as the day of worship, and because not enough data were associated with other days, I limited the analysis to those who attended religious services (if at all) on Sunday.

The survey on religiosity was sent to all bidders six weeks after the conclusion of the initial outbid data collection. The response rate was 5.56\%. A higher response rate was difficult to achieve because the survey was sent only once via email to each bidder and because institutional constraints made it impossible to send reminder emails. The re-bid rate among survey respondents $(28.4 \%)$ was close to the re-bid rate in the entire original dataset $(30.9 \%)$, providing some confidence against a response bias that could affect the interpretation of our results.

\subsection{Analysis}

A logistic regression analysis controlled for a number of factors that can affect the likelihood of rebidding once

\footnotetext{
${ }^{2}$ To avoid the effect of "multiple messages", I restricted analysis to the first instance of when a bidder received the charity vs. competitive message, creating a between-subjects design.

${ }^{3}$ The data available to the author code the responses to this survey question as a dichotomous variable: "regularly" vs. all other responses. As a result, the analysis compares "regular" vs. "non-regular" worshippers.
}

you have been outbid: (a) the current bid amount on the item, (b) time remaining in the auction, and (c) the total number of items in the auction. To eliminate the possibility of psychological influence (i.e., anchoring) based on potentially arbitrary values (Tversky \& Kahneman, 1974; $\mathrm{Ku}$, Galinsky, \& Murnighan, 2006), the analysis excluded items which listed a "reserve price" above $\$ 0$ (i.e., a minimal acceptable bid $>\$ 0) .{ }^{4}$ In order to eliminate the possibility that religious individuals were more susceptible to appeals for charity on Sundays only because the auction was related to their place of worship, the sample excluded auctions that were organized by religious organizations or were for religious causes. The final sample consisted of 812 outbid events for which I had survey data.

\section{Results}

I predicted that the appeal-to-charity message (but not the appeal-to-compete message) would be more likely to elicit additional bids among those who were high rather than low in religiosity, but that this effect would be limited to Sundays. This suggests an interaction between message type (charity vs. competitive), message day (Sunday vs. not a Sunday), and religiosity (regular vs. non-regular worshiper). As predicted, there was a statistically significant 3-way interaction [logistic regression, $\mathrm{B}=.74, \mathrm{SE}=.35$, Wald $=4.48, p=.017$, one-sided, $\mathrm{N}=812]$. Notably, there was no main effect of message type, day of the week, or religiosity, implicating the role of religious salience, but not religiosity, in predicting prosocial behavior.

The pattern of results is consistent with our hypothesis. On Sundays, whereas religious bidders were $40 \%$ likely to re-bid in response to an appeal to charity, nonreligious bidders were only $11.8 \%$ likely to re-bid in response to such appeals. Notably, on other days of the week, re-bidding in response to charity-appeals was almost identical among religious $(25 \%)$ and non-religious bidders $(27 \%)$, strongly suggesting that religious individuals are not more pro-social in general; they respond to appeals for help more so than non-religious individuals only when their religion is salient to them. (See Figure 1.). 5

\footnotetext{
${ }^{4}$ As a robustness check, I conducted a follow-up analysis which included items with reserve price $>\$ 0$, while controlling for reserve price in the model. The results were the same as those reported below.

${ }^{5}$ As Figure 1 reveals, not only does bidding by religious individuals increase on Sundays, but non-religious bidding also decreases. This result is consistent with my argument that religious individuals will be significantly more likely to respond to an appeal to charity, but only on Sundays. While it may be tempting to want to see no decrease in non-religious bidding on Sundays, consider the fact that we do not really know what the baseline level of re-bidding should be on Sundays. Indeed, the firm that provided this dataset informs the author that Sundays have a low "baseline level" of auction activity: the number of bids
} 
Figure 1: Bidding in response to an appeal in the charity (not the competitive) condition.

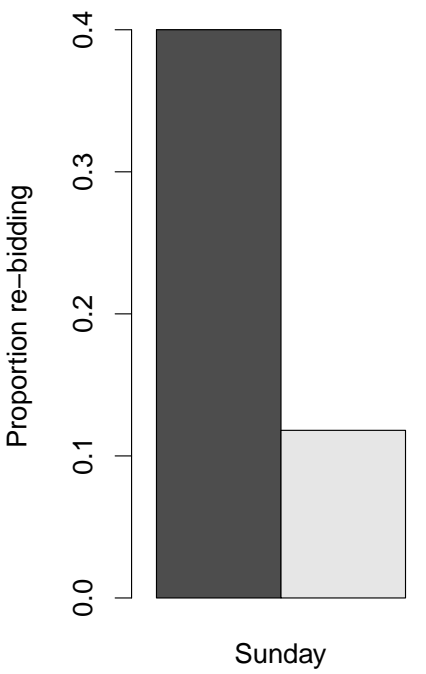

As expected, the pattern of results for the appeal-tocompetition message was markedly different. Appeals to competition were more effective on religious bidders than on non-religious bidders, but there was no day-of-week effect. These data serve to strengthen our conclusion regarding the role of religious salience (i.e., the Sunday Effect) on pro-social behavior among religious bidders. Specifically, it becomes difficult to argue that the Sunday Effect on pro-social behavior is simply an artifact of religious individuals differing from non-religious individuals in terms of how busy (or otherwise uninterested in online auctions) they are on Sunday. If that were the case, then the Sunday Effect would have been replicated in the appeal-to-competition condition. Instead, I find that the difference in how religious and non-religious bidders respond to the competition message is not affected by the day of the week.

While my analysis of the response to an appeal for charity compared Sunday to all other days of the week taken together, it is worth noting that the "Sunday Effect" does not extend, or spill-over, very much, if at all - forward to Monday or backwards to Saturday. Figure 2 shows the proportion of all the rebids and all the non-rebids that came from religious bidders on each day, in the charity (not the competitive) condition. (Note that this is a different perspective from that of Figure 1, which conditionalizes on bidding; Figure 2 takes into account "showing up to bid" as well.) Some evidence for spillover is that the proportion of rebids from religious bidders is second highest on Monday but the proportion of

is lower on Sunday than on any other day. Thus, religious bidders may be seen as not only responding more on Sundays than other days, but also as avoiding what might otherwise be a natural decline.
Figure 2: Proportion of rebids and non-rebids that came from religious bidders (charity condition).

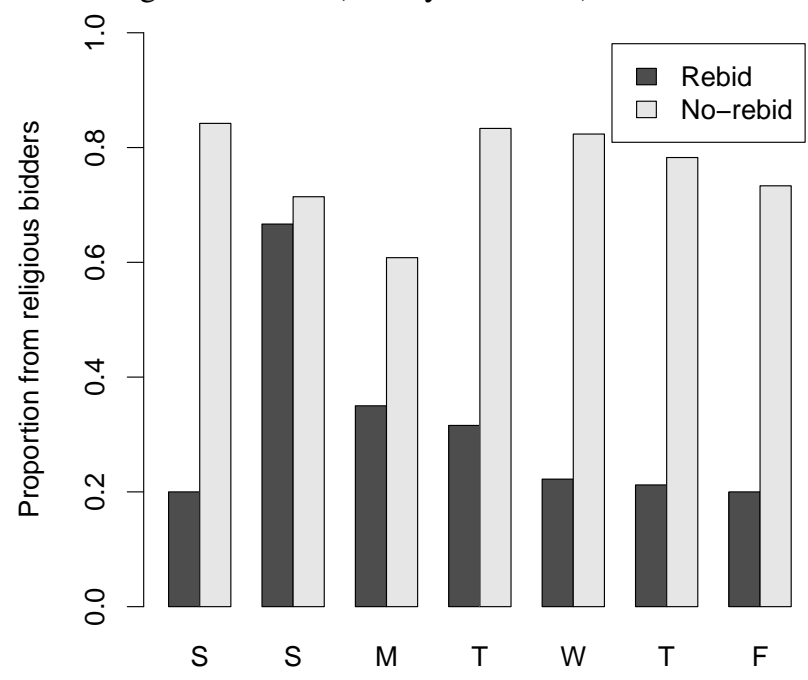

non-rebids is lowest on Monday. Still, the main effect is confined to Sunday itself.

\section{Discussion}

As predicted, responsiveness to appeals for pro-social behavior depended not simply on the religiosity of the individual (regular vs. non-regular worshipers), but on the salience of religion (Sunday vs. not) at the time of the appeal. The effect size is compelling: On Sundays, appeals to charity were over $300 \%$ more effective on religious individuals compared to non-religious individuals; on other days of the week (taken together), religious and non-religious individuals responded to such appeals almost identically. ${ }^{6}$

While the results clearly implicate the critical role of religious salience in predicting pro-social behavior in the current context, the results do not attempt to speak to whether religious vs. non-religious individuals are more pro-social in the aggregate. On the one hand, to the extent that religious individuals are more likely to be in situations where religion is made salient — and to be more likely to respond to religious cues (Bargh, Lombardi, \& Higgins, 1988) — this may lead them to perform

\footnotetext{
${ }^{6}$ These results resonate well with a fascinating study by Edelman (2009), who finds that overall subscription rates for adult (i.e., pornographic) entertainment websites do not differ between geographic regions where people attend religious services "regularly" vs. nonregularly, but a significantly smaller proportion of subscriptions among the former group are initiated on a Sunday. Edelman (2009: 217) notes: "A 1 percent increase in the proportion of people who report regularly attending religious services is associated with a 0.10 percent reduction in the proportion of purchases that occur on Sunday. This analysis suggests that, on the whole, those who attend religious services shift their consumption of adult entertainment to other days of the week."
} 
more pro-social behaviors in the aggregate. On the other hand, it is also possible that there are other, non-Godrelated stimuli that inspire pro-social behaviors among non-religious individuals (Shariff \& Norenzayan, 2007) which I cannot assess with this methodology.

The results of this study can be usefully compared to the results of Shariff \& Norenzayan's (2007) study of behavior in the Dictator Game. They found that participants sent more money to anonymous others, on average, when they had been primed with God-related concepts using a sentence unscrambling task. Across two experiments, Shariff \& Norenzayan (2007) reported a set of conflicting results: in Study 1, the prime influenced both "theists" and "atheists"; in Study 2, only "theists" were influenced. The authors speculate that the difference may have been caused by a stricter definition of atheism in Study 2, suggesting that they believe that for "real" atheists, priming God concepts should not be effective. The results of my study seem to support this conclusion, but there is an important distinction between these two papers. Shariff \& Norenzayan's (2007) used a laboratory setting to forcefully prime subjects just prior to playing the Dictator Game in order to test whether religious primes affect prosocial behavior among religious and non-religious individuals. In contrast, the current investigation leverages a naturally occurring behavioral distinction between religious and non-religious individuals - their likelihood of attending a place of worship on Sundays - to test whether and when religious individuals are more likely than non-religious individuals to behave pro-socially. As a result, unlike Shariff \& Norenzayan (2007), this paper is able to conclude that religious individuals do behave more pro-socially than non-religious people, but only when religious norms are likely to have been made salient (i.e., on Sundays). On the other hand, this paper does not try to speak to the issue of whether non-religious individuals would have also behaved more pro-socially had they been primed with religious (or other) norms.

A limitation of the current methodology is that, as with all behavioral studies, I have focused only on a specific aspect of pro-social behavior and have focused on a subset of the population that can afford to bid - and is inclined towards bidding - in charity auctions. (On the other hand, if charity-oriented individuals are overrepresented in our sample, then our results should provide a conservative estimate of the Sunday Effect.) A second limitation pertains to the low response rate to the survey on religiosity, which raises the question of whether responders might differ on some dimension that, if included, would create a four-way interaction, moderating (or reversing?) the three-way interaction I report. However, while it is conceivable that some religious people may show a reverse effect - e.g., contributing less to charity on Sunday because they have already contributed earlier in the day (perhaps with a collection plate) - such behavior entails an entirely different mechanism which does not contradict or refute the existence of a Sunday Effect driven by the salience of religious norms. A third limitation of the current analysis is that it is restricted to those who are likely to attend their religious place of worship on Sundays (if at all). While this group accounted for the majority of survey respondents in this study, followup analyses might evaluate the behavior of those who are more inclined to go on other days of the week. For example, might there be a "Saturday Effect" for Jewish people? Such an analysis is not possible here because the dataset provided to the author excluded detailed information on (the minority of) respondents who reported attending their place of worship on days other than Sunday.

Despite these limitations, the results provide some compelling evidence to contradict the long-held belief that religious individuals are inherently more pro-social, or are categorically more pro-social. To the extent that religiosity did affect pro-social behaviors in our study, the effect was indirect (i.e., it operated through religious salience) and its presence was not the modal case. Finally, the observed "Sunday Effect" on pro-social behavior provides a plausible alternative answer to why prior research has found an inconsistency between self-reports of pro-social behavior and observed pro-social behavior: if religious people are nicer only when religion is on their mind, such behavior may be missed in carefully crafted experiments that are specifically designed to purge religious primes from the laboratory setting.

\section{References}

Aarts, H., \& Dijksterhuis, A. (2003). The silence of the library: Environment, situational norm, and social behavior. Journal of Personality and Social Psychology 84(1), 18-28.

Allport, G. W. (1950). The individual and his religion. New York: Macmillan.

Allport, G. W. (1966). Religious context of prejudice. Journal for the Scientific Study of Religion, 5, 447457.

Annis, L. V. (1976). Emergency helping and religious behavior. Psychological reports, 39, 151-158.

Bargh, J. A., Chen, M., \& Burrows, L. (1996). The automaticity of social behavior: Direct effects of trait concept and stereotype activation on action. Journal of Personality and Social Psychology, 71, 230-244.

Bargh, J. A., Lombardi, W. J., \& Higgins, T. E. (1988). Automaticity of chronically accessible constructs in person $\mathrm{x}$ situation effects on person perception: It's just a matter of time. Journal of Personality and Social Psychology, 55(4): 599-605. 
Bargh, J. A. (2006). What have we been priming all these years? On the development, mechanisms, and ecology of nonconscious social behavior. European Journal of Social Psychology, 36(2): 147-168.

Batson, C. D., Oleson, K. C., Weeks, J. L., Healy, S. P., Reeves, P. J., Jennings, P., \& Brown, T. (1989). Religious personal motivation: Is it altruistic or egoistic? Journal of Personality and Social Psychology, 57, 873884.

Batson, C. D., Schoenrade, P., \& Ventis, W. L. (1993). Religion and the individual: a social-psychological perspective. New York: Oxford University Press.

Batson, C. D., \& Ventis, W. L. (1982). The religious experience: A social-psychological perspective. Oxford University Press.

Berger, J., \& Fitzsimons, G. (2008). Dogs on the street, pumas on your feet: How cues in the environment influence product evaluation and choice. Journal of Marketing Research, 45(1): 1-14.

Berger, J., Meredith, M., \& Wheeler, S. C. (2007). Contextual priming: Where people vote affects how they vote. Proceedings of the National Academy of Sciences, 105(26), 8846-8849.

Cline, V. B., \& Richards, J. M. (1965). A factor-analytic study of religious belief and behavior. Journal of Personality and Social Psychology, 1, 569-578.

Collins, A. M., \& Loftus, E. F. (1975). A spreadingactivation theory of semantic processing. Psychological Review, 82(6): 407-428.

Darley, J. M., \& Batson, C. D. (1973). From Jerusalem to Jericho: A study of situational and dispositional variables in helping behavior. Journal of Personality and Social Psychology, 27, 100-108.

Durkheim, E. (1912/1995). The Elementary Forms of Religious Life. New translation by Karen E. Fields. New York: The Free Press.

Edelman, B. G. (2009). Red Light States: Who Buys Online Adult Entertainment? Journal of Economic Perspectives 23(1): 209-220.

Evans-Pritchard, E. E. (1965). Theories of primitive religion. London: Oxford University Press.

Freud, S. (1927/1961). The future of an illusion, translated by J. Strachey. New York: Norton.

Friedrichs, R. W. (1960). Alter versus ego: An exploratory assessment of altruism. American Sociological Review, 25, 495-508.

Hertel, G., \& Kerr, N. L. (2001). Priming in-group favoritism: The impact of normative scripts in the minimal group paradigm. Journal of Experimental Social Psychology, 37(4): 316-324.

Higgins, E. T. (1996). Knowledge activation: Accessibility, applicability, and salience. In E. T. Higgins \& A. W. Kruglanski (Eds.), Social psychology: Handbook of basic principles (pp. 133-168. New York: Guilford.
James, W. (1902/1985). The varieties of religious experience: A study in human nature. Cambridge, MA: Harvard University Press.

Kay, A. C., Wheeler, S. C., Bargh, J. A., \& Ross, L. (2004). Material priming: The influence of mundane physical objects on situational construal and competitive behavioral choice. Organizational Behavior and Human Decision Processes, 95, 83-96.

Koenig, L. B., McGue, M., Krueger, R. F., \& Bouchard, Jr., T. J. (2007). Religiousness, antisocial behavior, and altruism: Genetic and environmental mediation. Journal of Personality, 75(2), 265-290.

Ku, G., Galinsky, A. D., \& Murnighan, J. K. (2006). Starting low but ending high: A reversal of the anchoring effect in auctions. Journal of Personality and Social Psychology, 90(6), 975-986.

Ku, G., Malhotra, D., \& Murnighan, J. K. (2005). Towards a competitive arousal model of decisionmaking: A study of auction fever in live and Internet auctions. Organizational Behavior and Human Decision Processes, 96(2), 89-103.

Langford, B. J., \& Langford, C. J. (1974). Church attendance and self-perceived altruism. Journal for the Scientific Study of Religion, 13, 221-222.

Malhotra, D. (2010). The desire to win: The effects of competitive arousal on motivation and behavior. Organizational Behavior and Human Decision Processes, 111: 139-146.

Morgan, S. P. (1983). A research note on religion and morality: Are religious people nice people? Social Forces, 61, 683-692.

Ross, L., \& Nisbett, R. (1991). The Person and the Situation: Perspectives of Social Psychology. New York: McGraw-Hill.

Shariff, A. F., \& Norenzayan, A. (2007). God is watching you: Priming god concepts increases prosocial behavior in an anonymous economic game. Psychological Science, 18(9), 803-809.

Skinner, B. F. (1969). Contingencies of reinforcement: A rhetorical analysis. New York: Appleton-CenturyCrofts.

Smith. R. E., Wheeler, G., \& Diener, E. (1975). Faith without works: Jesus people, resistance to temptation, and altruism. Journal of Applied Social Psychology, 5, 320-330.

Smith, W. R. (1891/1972). The religion of the Semites. New York: Schocken.

Tversky, A. \& Kahneman, D. (1974). Judgment under uncertainty: Heuristics and biases. Science, 185, 1124-1130.

Watson, P. J., Hood, R. W., \& Morris, R. J. (1985). Dimensions of religiosity and empathy. Journal of Psychology and Christianity, 4, 73-85. 